\title{
ANALISIS KEPUASAN PASIEN KULIT KELAMIN TERHADAP PELAYANAN FARMASI DI RSUD Dr. RM. DJOELHAM
}

\author{
Hervina $^{1}$, Juliandi Harahap ${ }^{2}$, Darwin Syamsul ${ }^{3}$ \\ ${ }^{1,3}$ Fakultas Kesehatan Masyarakat, Institut Kesehatan Helvetia \\ ${ }^{2}$ Fakultas Kedokteran, Universitas Sumatera Utara \\ Email: dr.hervina@gmail.com
}

\begin{abstract}
Assessing the quality of health services including the dimensions of reliability, responsiveness, assurance, empathy, and tangible. This research was carried out due to the decrease of patients visity to the Dermatology and Venereology Clinic in the past year. There were some patient disatisfaction for example, long waiting times for drugs, lack of available medicines, incomfortable and other. This study aims to analyze the satisfaction of skin and genital health clinic patients to pharmaceutical services based on the perspectives of patients and health care workers at Dr. R.M. Djoelham Binjai Regional Hospital. This research is a descriptive study with a qualitative approach, where data collection uses observation, interviews, field notes and documentation. Respondents were 10 informants consisting of 4 informants from patients who repeatedly, 2 informants from doctors, 2 informants from pharmacy/pharmacist services, 2 informants from hospital management. The results in this study show the patients dissatisfied with farmacy service at Dr. RM. Djoelham Binjai Hospital. Management of pharmaceutical prepations and clinical pharmacies (facilities and infrastructure) should be improved and add pharmacy service officers so that patients become more satisfied in Dr. R.M. Djoelham Binjai Hospital.
\end{abstract}

Keywords: Satisfaction analysis, patient satisfaction, pharmacy service quality, documentations, management of pharmaceutical.

\section{PENDAHULUAN}

Kesehatan merupakan kebutuhan dasar setiap manusia dan merupakan modal setiap warga negara dan setiap bangsa dalam tujuannya dan mencapai kemakmuran. Seseorang tidak bisa memenuhi kebutuhan hidupnya jika berada dalam kondisi tidak sehat, sehingga kesehatan merupakan modal setiap individu untuk meneruskan kehidupan secara layak (Bodhi, 2016).

Berdasarkan Surat Keputusan Menteri Kesehatan Nomor 72 Tahun 2016 tentang Standar Pelayanan Farmasi
Rumah Sakit menyebutkan bahwa pelayanan kefarmasian di rumah sakit merupakan bagian yang tidak terpisahkan dari sistem pelayanan kesehatan rumah sakit yang berorientasi kepada pelayanan pasien, penyediaan sediaan farmasi, alat kesehatan, dan bahan medis habis pakai yang bermutu dan terjangkau bagi semua lapisan masyarakat termasuk pelayanan farmasi klinik (Permenkes, 2016).

Pelayanan instalasi farmasi yang bermutu adalah pelayanan kesehatan yang dapat memuaskan setiap 
pemakaian jasa pelayanan sesuai dengan tingkat kepuasan pasien (Creswell, 2017). Hasil penelitian menurut Noprilyana (2017) menunjukkan bahwa nilai koefisien terhadap kepuasan pasien pada pelayanan farmasi sebesar $>75 \%$. Dimensi yang memiliki pengaruh yang signifikan terhadap kepuasan pasien yaitu dimensi tampilan fisk (tangible) diperoleh nilai $89,25 \%$, kehandalan petugas farmasi (reliability) diperoleh nilai 86,00\%, jaminan (assurance) diperoleh nilai $81,69 \%$, daya tanggap (responsivenesess) diperoleh nilai $82,85 \%$, dan empati (empathy) diperoleh nilai 80,46\% (Putri, 2017).

RSUD Dr RM Djoelham Binjai merupakan rumah sakit pemerintah rujukan tipe B dan sudah menjadi Badan Layanan Umum (BLU) yang dituntut untuk memberikan pelayanan maksimal dengan biaya minimal. Bersertifikat terakreditasi paripurna yang mendapat pengakuan dari pemerintah bahwa semua hal yang dikerjakan sudah sesuai standar. Sarana dan prasarana yang dimiliki rumah sakit berfokus pada keselamatan pasien. Mempunyai 18 klinik rawat jalan yang terdiri atas 14 klinik spesialis, 2 klinik subspesialis, serta klinik gigi dan klinik HIV. Semua klinik yang ada di RSUD Dr RM
Djoelham Binjai berupaya memberikan pelayanan yang terbaik sesuai standar pelayanan klinik untuk memberi kepuasan pasien tanpa membedakan status (Profil RSUD Dr. Djoelham, 2016).

Berdasarkan data yang diperoleh dari bagian rekam medis RSUD Dr RM Djoelham Binjai dilihat dari jumlah kunjungan pasien rawat jalan klinik kesehatan kulit dan kelamin pada bulan Oktober sampai bulan Desember pada tahun 2018 terdapat penurunan jumlah kunjungan pasien rawat jalan pada setiap bulannya. Penurunan kunjungan tersebut menunjukan adanya kemungkinan ketidakpuasan pasien dengan pelayanan yang diberikan. Sehingga dirumuskan masalah penelitian: bagaimana kepuasan pasien terhadap pelayanan farmasi di klinik kulit dan kelamin di Rumah sakit Dr. RM Djoelham Binjai?.

Disamping itu di pelayanan farmasi terdapat keluhan mengenai pelayanan pasien dalam operasional sehari-hari, mengenai waktu tunggu yang lama, keterbatasan stok obat, mahalnya obat, ruang tunggu yang kurang nyaman yang tidak tersedia kipas angin/AC, termasuk banyaknya pasien klinik kesehatan kulit dan kelamin mengeluh obat yang diberikan dari pihak 
pelayanan farmasi tidak sesuai dengan resep yang berikan dokter, dengan alasan keterbatasan jumlah obat yang dimiliki dan tidak tersedianya obat di pelayanan farmasi.

Sampai saat ini, pihak rumah sakit belum pernah melakukan pengukuran kepuasanan pasien rawat jalan terhadap pelayanan farmasi. Oleh sebab itu peneliti ingin meneliti bagaimana pengelolaan sediaan farmasi untuk obat di klinik kesehatan kulit dan kelamin mengapa bisa terjadi adanya keterbatasan obat (obat topikal yang diracik dan beberapa obat yang harus diberikan kepada pasien), tidak tersedianya obat dan juga apakah pada pelayanan farmasi klinik sudah melaksanakan pelayanan sesuai standar yang diberikan kepada pasien seperti pemberitahuan obat dengan instruksi khusus (maintenance/tapering off) yang sering diberikan pada pasien dengan gangguan kulit yang kronis,dan sebagainya sehingga perlunya peranan bagian pelayanan farmasi agar dapat menghindari efek samping penggunaan obat dan lain-lainnya terhadap pasien klinik kesehatan kulit dan kelamin. Dan juga ingin mengetahui apakah berkurangnya kunjungan pasien ada hubungannya juga dengan keadaan tersebut, dan jika ada hal lain yang nantinya kami jumpai pada penelitian ini bisa menjadi masukan untuk meningkatkan mutu pelayanan di RSUD Dr RM Djoelham Binjai.

Berdasarkan uraian di atas perlu dilakukan penelitian yang bertujuan untuk menilai secara kualitatif kepuasan pasien atas pelayanan farmasi di RSUD Dr RM Djoelham Binjai berdasarkan 5 dimensi yaitu kehandalan (reliability), daya tanggap (responsiveness), jaminan (assurance), empati (empathy), dan bukti fisik (tangibles).

\section{METODE PENELITIAN}

Penelitian ini merupakan jenis penelitian non eksperimental, dengan pendekatan kualitatif. Informan penelitian ini sebanyak 10 informan (kunci dan utama), terdiri dari 4 orang pasien lama yang berobat jalan ke klinik kesehatan kulit dan kelamin, 2 orang dokter, 2 orang petugas pelayanan farmasi, 2 orang manajemen rumah sakit. Data diambil melalui wawancara.

\section{HASIL PENELITIAN}

Setelah dilakukan wawancara pada 10 orang informan untuk melihat kepuasan pasien klinik kesehatan kulit dan kelamin terhadap kepuasaan pasien di RSUD Dr. RM. Djoelham Binjai pada 
dimensi kehandalan, daya tanggap, jaminan, empati dan bukti fisik.

\section{Dimensi Kehandalan}

Dimensi ini mengukur bagaimana pelayanan yang di berikan kepada pasien secara tepat, segera dan tidak menunggu lama, terpercaya serta memuaskan termasuk bagaimana petugas memantau keberhasilan obat yang diberikan sebelumnya. Hasil dari wawancara pada pasien menyatakan "...kami rasanya masih lama menunggu obat, yang sesuai nomor antrian." (pasien 1)"...obat lama di dapat karena harus mengganti dengan yang lain karena habis,kami harus bekerja lagi." (pasien 4), tetapi pernyataan ini tidak sesuai dengan beberapa pernyataan manajemen dan apoteker rumah sakit yang menyatakan pelayanan farmasi baik, "...pelayanan yang kami berikan sudah tepat dan segera mungkin". (manajemen 1). "...petugas pelayanan farmasi juga di tempatkan sesuai dengan pendidikannya...kami sudah berusaha semaksimal mungkin tetapi memang diperlukan waktu untuk membuat pasien lebih puas". (manajemen 2, apoteker1).

\section{Dimensi Daya Tanggap}

Dimensi ini menunjukkan bagaimana petugas pelayanan farmasi cepat, jelas dan tanggap dalam memberi pelayanan. Hasil wawancara dimensi daya tanggap pada pasien dan dokter menyatakan, “...hendaknya petugas pelayanan farmasi harus cepat tanggap dalam keadaan atau kondisi apapun dan jangan pasien yang bertanya dulu."(pasien3). "...hendaknya menyediakan obat yang belum pernah tersedia dan menyediakan obat sesuai dengan pasien butuhkan". (dokter 1).

Sedang sebagian informan dari pihak farmasi dan manajemen informasi menyatakan, "... tetapi kadangkala pada saat pasien ramai sulit untuk menjelaskan berulang kali atau pasien memang tidak mendengarnya”. (apoteker 1, 2), “...kami slalu mengingatkan agar cepat tanggap akan kebutuhan pasien".'”...termasuk juga obat yang dibutuhkan, menjelaskannya." (manajemen2).

\section{Dimensi Jaminan}

Dimensi ini menyatakan tentang jaminan bagaimana kemampuan petugas mampu memberi rasa aman, nyaman, percaya dan yakin serta petugasnya terampil dan sopan. Hasil wawancara dimensi jaminan pada pasien menyatakan. " "...jangan bosan memanggil lengkap agar tidak salah memberi obat". (pasien 2,)”...hendaknya jangan selalu mengganti obat yang biasa 
kami minum,jadi kami gak ragu minum obatnya”. (pasien 3). “...petugas belum maksimal mengidentifikasi kami sebelum menyerahkan resep". (pasien 4), Sedangkan wawancara pada beberapa informan pihak farmasi dan manajemen rumah sakit menyatakan, "...slalu mengingatkan petugas untuk memanggil I mengidentifikasi pasien berulang agar tidak terjadi kesalahan pemberian obat". (apoteker 1,2), " "...selalu mendukung petugas agar semua pasien bisa merasa aman, nyaman, yakin dengan ketrampilan dan kemampuan petugas". (manajemen1,2).

\section{Dimensi Empati}

Dimensi ini menyatakan tentang bagaimana petugas pelayanan farmasi melakukan komunikasi dengan baik, perhatian, penuh kesabaran, mengetahui akan kebutuhan pasien serta melayani tanpa memandang status sosial pasien, pada dimensi ini juga memegang peranan yang penting karena dengan komunikasi yang baik, sabar, pasien sudah merasa senang sehingga akan membantu penyembuhan selain obat yang diberikan oleh dokter.

Hasil wawancara dimensi empati pada pasien menyatakan. “...komunikasi terjalin dengan baik jikalau tidak banyak pasien, tetapi kurang baik jika banyak pasien." (pasien 4)"... petugas jarang menegur kami terlabih dulu,jika kami masuk ke apotek untuk menyerahkan resep obat". (pasien 4), Sedangkan beberapa informan apoteker menyatakan, "...kami menjamin seluruh petugas pelayanan farmasi memperlakukan sama setiap pasien tanpa memandang status sosial ,dan memperhatikan setiap keinginan tanpa pilih-pilih siapa mereka”. (manajemen dan apoteker. "...selalu berusaha membuat pasien puas". (apoteker 1).

\section{Dimensi Bukti Fisik}

Pada dimensi ini menyatakan tentang bukti fisik artinya bagaimana keadaan pelayanan farmasi rumah sakit dilihat dari kebersihan dan kenyamanan, alat bantu untuk komunikasi/memanggil pasien, ruang tunggu, toilet, penampilan petugas maupun lokasi pelayanan serta paling penting adalah sediaan farmasi/obat yang mencukupi kebutuhan pasien. Jika ruang tunggu yang nyaman akan membuat pasien betah atau suka menunggu di sana. Hasil wawancara dimensi bukti fisik pada pasien dan dokter yang menyatakan bahwa, “...kami melihat ruang tunggu dan toilet tidak bersih AC sering rusak, penampilan petugas pelayanan farmasi kurang rapi, tidak pake seragam”. (pasien 1)”... 
tetapi yang paling penting persediaan obat harus selalu terpenuhi dan obat yang belum tersedia untuk kedepannya sudah ada”. (pasien 3) “...lokasi jalan menuju ke tempat pengambilan obat agar diperluas." (pasien 4).,"...kami berharap obat selalu tersedia, dan obat yang memang dibutuhkan pasien mohon disediakan" (dokter 1,2), Begitu juga dengan hasil wawancara peneliti pada farmasi dan manajemen rumah sakit menyatakan, "’..kami sudah memberikan masukan agar menambah tempat pelayanan pengambilan obat untuk rawat jalan dan rawat inap". (apoteker 1)"...untuk keadaan ruang tunggu, toilet ,AC, memang masih kurang baik dan obatpun masih banyak kekurangan". "...kami terus berusaha untuk memperbaiki segala kekurangan”. (apoteker 2), “...memang soal kebersihan, kenyamanan ruang tunggu dan toilet masih kurang... kami berusaha untuk meningkatkannya dan mengenai lokasi menuju jalan ke sana masih sempit karena dekat dengan parkiran sepeda motor...petugas menurut kami sudah rapi penampilannya...sedangkan untuk persediaan obat masih terus kami usahakan sesuai kebutuhan pasien”. (manajemen 1)".

\section{PEMBAHASAN}

\section{Dimensi Kehandalan}

Hasil penelitian dimensi kehandalan, informan pasien menginginkan pelayanan lebih cepat, sehingga pasien tidak menyuruh anak atau keluarga untuk menggambil obat, pasien yang lansia hendaknya mendapat keringanan untuk mendapat obat lebih dahulu dan agar menyediakan obat agar tidak kehabisan.Jadi pada dimensi ini sebagian informan tidak puas. Penelitian ini sesuai dengan penelitian Fina Aryani (2015) di RS IBNU SINA Pekanbaru, didapatkan hasil pasien tidak puas dengan pelayanan RS Ibnu Sina Pekanbaru untuk dimensi handal. Penelitian ini tidak sesuai dengan Novariyatin S (2018) di RSUD Dr. Nurjani Sampit, didapatkan pasien merasa puas untuk dimensi handal dengan persentase $65,6 \%$. Penelitian ini juga tidak sesuai dengan penelitian Wiguna (2018) di RSUD Ir. Soekarno Sukoharjo, didapatkan pasien merasa puas untuk dimensi handal.

\section{Dimensi Daya Tanggap}

Hasil penelitian dimensi daya tanggap, informan mengharapkan walaupun lagi banyak pasien, hendaknya petugas menjawab dan memberi penjelasan jangan terburu-buru, karena 
usia pasien yang menunggu obat bervariasi dari yang muda sampai lansia. Pada dimensi ini informan pasien tidak puas. Penelitian ini tidak sesuai dengan penelitian Aryani (2015) di RS IBNU SINA Pekanbaru, didapatkan hasil pasien puas dengan pelayanan RS Ibnu Sina Pekanbaru untuk dimensi daya tanggap. Penelitian ini tidak sesuai dengan penelitian Novariyatin S (2018) di RSUD Dr. Nurjani Sampit, didapatkan pasien merasa puas untuk dimensi daya tanggap dengan persentase 67,6\%. Penelitian ini juga tidak sesuai dengan penelitian Wiguna (2018) di RSUD Ir. Soekarno Sukoharjo, didapatkan pasien merasa puas untuk dimensi daya tanggap.

\section{Dimensi Jaminan}

Pada dimensi ini pelayanan yang baik, pelayanan dengan reputasi, keterampilan atau kemampuan seluruh staf farmasi yang membuat pasien merasa terjamin bisa sembuh serta datang berobat dan mengambil obat di rumah sakit ini. Pihak manajemen dan apoteker sudah berusaha memberikan yang terbaik, tetapi sebagian informan tidak puas, diharapkan petugas lebih teliti dalam mengidentifikasi pasien dan hendaknya pihak rumah sakit menyiapkan obat sesuai dengan yang diresepkan dokter. Penelitian ini sesuai dengan penelitian Aryani (2015) di RS IBNU SINA Pekanbaru, didapatkan hasil pasien tidak puas dengan pelayanan RS Ibnu Sina Pekanbaru untuk dimensia asuransi. Penelitian ini tidak sesuai dengan penelitian Novariyatin S (2018) di RSUD Dr. Nurjani Sampit, didapatkan pasien merasa puas untuk dimensi jaminan dengan persentase $72,7 \%$. Penelitian ini juga tidak sesuai dengan penelitian Wiguna (2018) di RSUD Ir. Soekarno Sukoharjo, didapatkan pasien merasa puas untuk dimensi jaminan.

\section{Dimensi Empati}

Dimensi ini pasien akan merasa senang jika di perhatikan, menjalin komunikasi yang baik dengan petugas pelayanan farmasi tanpa memandang status sosial mereka. Dengan sabar mendengar keluhan mereka, hal ini akan membuat mereka senang berobat dan mengambil obat di rumah sakit ini. Hal ini membuat informan merasa puas. Penelitian ini sesuai dengan penelitian Aryani (2015) di RS IBNU SINA Pekanbaru, didapatkan hasil pasien puas dengan pelayanan RS Ibnu Sina Pekanbaru untuk dimensi empati.

Penelitian ini sesuai dengan penelitian Novariyatin (2018) di RSUD Dr. Nurjani Sampit, didapatkan pasien 
merasa puas untuk dimensi empati dengan persentase $66,6 \%$. Penelitian ini sesuai dengan penelitian Wiguna (2018) di RSUD Ir. Soekarno Sukoharjo, didapatkan pasien merasa puas untuk dimensi empati.

\section{Dimensi Bukti Fisik}

Dimensi ini suasana tempat seperti ruang tunggu, toilet yang tersedia di pelayanan farmasi sangat mendukung agar pasien merasa nyaman, betah, senang untuk menunggu obat di sana. Selain itu di dalam ruang tunggu ada bahan bacaan atau poster di dinding berisi masalah kesehatan sehingga jika pasien membacanya dapat menambah ilmu pengetahuan buat mereka. Pasien akan merasa puas jika obat yang diresepkan tersedia dan tidak perlu membeli di luar jika obat itu memang sangat mereka butuhkan.Petugas yang berpenampilan bersih dan rapi akan membuat pasien merasa senang melihatnya. Informan manajemen, apoteker, mengakui banyak kekurangan di sini dan pasien tidak puas pada dimensi ini. Penelitian ini bertolak belakang dengan penelitian Aryani (2015) di RS IBNU SINA Pekanbaru, didapatkan hasil pasien puas dengan pelayanan RS Ibnu Sina Pekanbaru untuk dimensia bukti fisik.
Penelitian ini tidak sesuai dengan denan penelitian Novariyatin (2018) di RSUD Dr. Nurjani Sampit, didapatkan pasien merasa puas untuk dimensi bukti fisik dengan persentase $68,6 \%$. Penelitian ini juga tidak sesuai dengan penelitian Wiguna (2018) di RSUD Ir. Soekarno Sukoharjo, didapatkan pasien merasa puas untuk dimensi bukti fisik.

\section{KESIMPULAN}

Sebagian besar informan tidak merasa puas pada pelayanan farmasi dari setiap dimensi, hal ini mungkin dikarenakan informan/responden lebih merasa terbuka untuk berbicara apa yang mereka rasakan dan juga pengalaman mereka dalam menerima pelayanan farmasi, hal ini bisa terjadi karena setiap informan mempunyai harapan/keinginan yang berbeda- beda. Pihak rumah sakit dapat menyediakan obat sesuai dengan jumlah pasien dan menyediakan obat yang belum pernah tersedia tetapi dibutuhkan pasien (sarana), serta penambahan jumlah apoteker dan tenaga teknis kefarmasian, untuk meningkatan mutu pelayanan rumah sakit, khususnya pelayanan farmasi (prasarana).

\section{SARAN}

Diharapkan pihak rumah sakit menambah jumlah staf/petugas di pelayanan farmasi menurut Permenkes 
nomor 72 tahun 2016 sesuai tipe dari RSUD Dr RM Djoelham Binjai yaitu tipe B agar bisa melayani pasien secara maksimal, meningkatkan pelayanan farmasi pada setiap dimensi, agar pasien merasa puas dan kembali lagi berobat ke rumah sakit, serta meningkatkan manajemen pengelolaan sediaan farmasi dan farmasi RSUD Dr RM Djoelham Binjai.

Peneliti selanjutnya untuk mengetahui kepuasan pasien terhadap unsur pelayanan yang lain yang belum diteliti oleh peneliti sebelumnya. Bagi peneliti menjadi pengalaman berharga dalam mengaplikasikan ilmu yang diperoleh selama mengikuti pendidikan serta memperluas wawasan pengetahuan tentang tingkat kebutuhan, harapan, serta kepuasan pasien dalam pelayanan farmasi.

\section{DAFTAR PUSTAKA}

Pareraway DC. Tjitrosantoso H. Bodhi W. 2016. Analisis Kepuasan Pasien Rawat Jalan Dalam Pelayanan Kefarmasian Di Instalasi Farmasi RSUP. Prof. Dr. R. D. Kandau Manado 2016. Jurnal Ilmiah Farmasi Unsrat. Manado.

Peraturan Menteri Kesehatan Republik Indonesia Nomor 72 Tahun 2016 Tentang Standar Pelayanan Kefarmasian di Rumah Sakit.

Creswell JW. 2017. Research Design Pendekatan Kualitatif, Kuantitatif dan Mixed.Cetakan 2. Yogyakarta: Pustaka Pelajar.

Putri NAE. 2017. Analisis Tingkat Kepuasan Pasien Terhadap Pelayanan Farmasi di Instalasi Farmasi Satelit Rawat Jalan RSUD Cilacap [Skripsi]. Universitas Muhammadiyah, Yogyakarta.

Profil RSUD Dr RM Djoelham Binjai Tahun 2016.Sumatera Utaral

Aryani F. 2015. Analisa Kepuasan Pasien Rawat Jalan terhadap Kualitas Pelayanan di Instalasi Farmasi RS Ibnu Sina Pekanbaru. Sekolah Tinggi Ilmu Farmasi Riau. Pekanbaru.

Novaryatin S, dkk. 2018. Tingkat Kepuasaan Pasien Terhadap Pelayanan Kefarmasian di RSUD Dr. Nurjani Sampit. Universitas Muhammadiyah Palangkaraya. Kalimantan Tengah.

Wiguna YA. 2018. Analisis Tingkat Kepuasaan Pasien BPJS Terhadap Pelayanan di Instalasi Farmasi Rawat Jalan RSUD Ir. Soekarno Sukoharjo Tahun 2018. Universitas Muhammadiyah Surakarta. Surakarta. 